\title{
Career Deviation among Public School's Principals in Tulkarem from Teachers' Point of View
}

\author{
Jafar wasfi Abu Saa ${ }^{1}$ \\ ${ }^{1}$ Department of Technological Education, Palestine Technical University- Kadoorie, Tulkarem, Palestine. \\ Correspondence: Jafar wasfi Abu Saa, Department of Technological Education, Palestine Technical University- \\ Kadoorie, Palestine. E-mail: jaafarabusaa@yahoo.com
}

Received: November 26, 2019

Accepted: December 16, 2019 Online Published: December 18, 2019

doi:10.5539/mas.v14n1p12

URL: https://doi.org/10.5539/mas.v14n1p12

\begin{abstract}
This study aimed to identify the level of career deviation commonness among school's principals from the point view of teachers in Tulkarem governorate, as well as recognizing that commonness according to the gender, qualifications and practical experience variables. The results of the study showed that the teachers' estimates of the prevalence of career deviation among the principals of the public schools in Tulkarm governorate were medium, the results also indicated that there were no statistically significant differences between the averages of the sample estimates of the functional deviation due to the variables (gender, academic qualification, years of experience). Based on the previous results a number of recommendations were proposed, the most important of them were: To enhance and promote the culture of commitment among principals.
\end{abstract}

Keywords: career deviation, public school's principals, tulkarm governorate.

\section{Introduction}

The phenomenon of career behaviour deviation is one of the concepts which human societies despite their differences have suffered from, that is because of the multitude of its methods, and the diversity of its ways of penetrating countries and societies and even institutions. It sometimes takes the shape of bribery, and sometimes takes the shape of embezzlement, and other takes the shape of favoritism, fraud, or deviation from the right, abuse of power and damage of the public interest, or abuse of influence, or manipulation of public money and wasting it, all of these aspects of career deviation indicate the spread of this phenomenon in varying proportions between societies and states, which in the end spoils the body of those societies (Abu Amrah, 2011).

According to (Bollin, 2011), Career deviation is: "A global phenomenon that includes the exploitation of the public career and public resources to achieve personal or collective benefits contrary to honor and official regulations, whether this exploitation is from a personal motivation of the employee himself, or as a result of pressure exercised by individuals or institutions from within or outside the government apparatus, Individually or collectively". The researcher thinks that career deviation is certainly indicative of a moral crisis in behavior that reflects defects in values and a deviation in attitudes from the level of controls and straight standards which leads to making administrative system lose their actual entity aimed to achieving the interests of corrupt system of workers coexisting within the system. Although the system maintains the entity's uniformity, its unified rules and regulations of work have been replaced by conflicting work rules and procedures that serve the objectives and interests of the corrupt groups that coexist in the system (Judge\& Kammeyer-Mueller, 2011).

The human element is of great importance, especially in school education in Palestine. The dealing with this element is sometimes contaminated with defects resulting from many different social and organizational factors. Therefore, it was necessary to identify the factors that cause this defect by the principal during his work. Therefore, this study was used to identify the commonness of career deviation among the principals in Tulkarem governorate from the point of view of the teachers.

\section{Problem Statement}

Career deviation is a pervasive phenomenon among individuals and people, where it became influential on all of life aspects in general and on the educational process especially, the problem of career deviation among principals is considered as a compound phenomenon the educational fields are overlapping in it, as well as in economic, social, political fields. 
This deviation is a result of a number of factors, such as, lack of religious persuasion, lack of national spirit in some principals, poor salaries, and lack of follow-up by senior administrations.

Therefore, the problem of the study is limited to the following questions:

The first question: What are the manifestations of career deviation among the principals of public schools in Tulkarem from the point of view of teachers?

The second Question: Do the different aspects of career deviation among the principals of public schools in Tulkarm differ from the teachers' point of view according to the following variables: (scientific qualification, gender, years of experience)?

\section{Literature Review and Related Studies.}

The manifestations of the career deviation can be divided into four aspects which are, organizational deviations, behavioral deviations, and financial deviations, criminal deviations, these deviations will be reviewed successively as follows:

\subsection{Organizational Deviations}

Organizational deviations mean that violations which are done by the principals during the performance of his duties, which are mainly related to the work and regularity, including disrespect of work time, that's when the principal considers the time and how many hours and how much left to return to his home, regardless of his production or work (Zaccaro et al., 2001).

As well as the principal's abstention to perform the work required of him which is his refusal to perform the work given to him by his superiors, or to refrain from doing his job or doing it improperly or delaying of performance, and the reasons for the spread of this phenomenon can be attributed to the low salaries they receive, which do not commensurate with the effort required to complete their work (Robbin, 2006).

Also laxity and laziness can be added to the organizational deviations principals practice. And what encourages them to work only the financial motivation or personal interest on the one hand, or fear on the other hand, as that the failure to comply with the orders and instructions of the superiors, especially when the chiefs act in some ways towards principals, such as depriving them of bonus or incentive reward, for example, or discrimination in promotions and incentives. This may result in the principals being aggressive towards his superiors, disobeying their orders, disrespecting them and searching for outlets and excuses for not obeying their orders (Jabaal, 2015).

The negativity may be another manifestation of career deviation which is known as the principal's lack of opinion and indifference, and does not tend to innovation and development, and avoids participation in decision-making, which reaches the principals to the extent of the conviction to receive instructions from others without discussion, in addition to isolationism, and the unwillingness of some principals to cooperate with their colleagues, and they do not encourage them to work together and avoid contact with other people, and the principals does not want to be associated with anyone else.

The irresponsibility is also an organizational deviation, principals may try to avoid responsibility and this is demonstrated by the transfer of papers from a lower level of management or vice versa to avoid signatures for not taking responsibility (McCartney \& Campbell, 2006).

The disclosure of the secrets of the work is one of the most important organizational deviations, when the principals inform the teachers of the confidential reports written by educational supervisors on them, that leading to an increase in the degree of conflict between the teacher and supervisor about what was written in these reports, or some principals make false or uncertain statements to the media, which may cause damage to the school. (Tabash, 2009).

Al-Shammimari (2011) discussed that the principal may occupy his time with things that unrelated to the work, such as filling his time with phone calls, browsing the internet, reading magazines and newspapers, and doing some special work inside their offices and using the organization's tools to accomplish these tasks. Consequently, work time is wasted on matters unrelated to work.

Yahaya et al. (2010) also indicated that some departments, both public and private suffer from the absence from official work, whether with excuse or without excuse, early exit from work, delay in attendance at the beginning of official work and the early exit of principals. 


\subsection{Behavioral Deviations}

Behavioral deviations are the administrative violations committed by the principal and relating to his personal conduct, including the failure to maintain the dignity of the job, such as the committing of indecent assault in the workplace or outside the workplace, the use of drugs, exploitation or involvement in honor crimes (Bolin, 2001).

In addition to the misuse of power, where the principal is given the freedom to exercise his powers to decide what he considers to be a public good, and may use these powers to achieve personal interests at the expense of the school interest (Shermerhorn, 2014).

Gentry et al. (2007) pointed out that the nepotism and favoritism that the principal uses in the case of mandate, transfer, promotion, or bonus, or in the sake of the satisfaction of his boss at work, this is considered one of the most important phenomena of behavioral deviations.

\subsection{Financial Deviations}

It refers to those financial and administrative violations related to the work assigned to the principal. These violations are as follows: Violation of the financial rules and stipulations in the school and violation of the instructions of the financial control agencies such as, imposing fines and excessive use of public funds and criminal deviations (Gentry et al., 2015).

Kruger (2016) pointed out that bribery, embezzlement of public funds, and forgery in official publications are other manifestations of financial deviations, are indirect attacks on state authority, administration and school.

\subsection{Related Studies}

In the light of the researcher's review of previous studies in this field, he found many studies that held the subject of career deviation, which are:

(Omar, 2011) conducted a research on the relationship between perverse behavior in the workplace and some associated factors such as work stress, job satisfaction. And he concluded that there is a positive correlation between job satisfaction and perverse behavior in the workplace, but there are no differences in behavior deviation in the workplace due to gender.

(Salami, 2010) conducted a research on the relationship between stress, negative behaviors at work, and their negative impact on efficiency. And he concluded that there is a direct relationship between work pressure and negative behavior at work, and there is a positive correlation between negative behavior in work and negative work efficiency.

(Al-Thaqafi, 2008) conducted a research on the Degree of the practice of the career deviation in the public schools in Taif governorate from the point of view of the educational supervisor, the principal of the school and the teacher. And he concluded that there is a medium degree of career deviation among teachers in the public schools at Al-Taif governorate.

\section{Methodology}

The researcher used the descriptive approach which based on collecting, analyzing, organizing and arranging the problem related information, and then explaining it to achieve the objectives of the study, this is due to its suitability for this study.

\subsection{Sample Size and Sampling}

The study population consists of all (2762) teachers in the public schools in Tulkarm Governorate. A random sample of (221) teachers was selected in the public schools in Tulkarm Governorate.

\subsection{Research Tool}

The study tool was prepared, which included the paragraphs concerning the prevalence of the career deviation, and its number (24) paragraphs. The validity of the tool was verified by a number of reviewers. And the questionnaire was presented to a group of specialists in the Palestinian universities. The Cronbach's Alpha test has a value of $(0.90)$, which indicates high validity.

\subsection{Study Variables}

Independent variables:

Variable of sex and it has two levels: (male, female). Variable of scientific qualification and it has four levels: (Diploma, Bachelor, Bachelor + Diploma Master and above). - Variable of years of experience and it has four levels: (less than 5 years, 5-10 years, 11-15 years, more than 15 years).Dependent variable: Career deviation. 


\subsection{Statistical Processing}

Statistical data were processed using the SPSS program. The following measure was used to determine the degree to which the behavior of the principals of public schools in Tulkarem governorate is described.

Low grade: If the arithmetic mean of the paragraph is equal to or less than (2.33).

Medium: If the arithmetic mean is limited between (2.34- 3.67).

Large degree: If the arithmetic mean is higher than (3.67).

\section{Findings and Results}

\subsection{The First Question}

"What are the manifestations of career deviation among the principals of public schools in Tulkarem from the point of view of teachers?"

To answer this question, the researcher calculated the arithmetical averages and the standard deviations of the responses of the sample members of the study from the teachers in Tulkarm governorate on the questionnaire paragraphs that measure principals career deviation, as shown in Table (1).

Table 1.

\begin{tabular}{|c|c|c|c|c|}
\hline$N$. & Paragraphs & Mean & $\begin{array}{l}\text { Standard } \\
\text { deviation }\end{array}$ & Degree \\
\hline 12 & The principal criticizes his colleagues in their absence. & 3.66 & 1.12 & Medium \\
\hline 9 & The principal intervenes in favor of some of the students who fail. & 3.46 & 1.04 & Medium \\
\hline 6 & The principal tries to hear everything the teachers are talking about. & 3.41 & 1.05 & Medium \\
\hline 8 & $\begin{array}{l}\text { The principal distinguishes between teachers according to their } \\
\text { loyalty to him regardless of their competencies. }\end{array}$ & 3.35 & 1.36 & Medium \\
\hline 3 & The principal makes decisions within the school individually. & 3.28 & 1.17 & Medium \\
\hline 11 & The principal refers to the nepotism in case of transfer or promotion. & 3.20 & 1.18 & Medium \\
\hline 1 & The principal avoids taking responsibility in school. & 3.11 & 1.20 & Medium \\
\hline 7 & The principal declares school secrets to the local community. & 2.31 & 0.72 & low \\
\hline 16 & The principal is aggressive towards his colleagues. & 2.26 & 0.70 & low \\
\hline 19 & The principal uses the property of the school for special purposes. & 2.20 & 0.77 & low \\
\hline 22 & The principal neglects to develop himself professionally. & 2.19 & 0.86 & low \\
\hline 18 & The principal falsifies the official papers at the school. & 2.17 & 0.78 & low \\
\hline
\end{tabular}


The principal exploits his job in achieving personal interests.

2 Poor completion of the principal of work in a timely manner. hours.
The principal is indifferent in his work.

It is clear from Table (1) that the sample of the study for the phenomenon of career deviation among the principals of the public schools in Tulkarm was medium to paragraphs $(1,11,3,8,6,9,12)$, respectively. Between (3.66-3.11), while the estimates of the sample of the study were low on $(21,20,17,15,24,14,4,23,5,2,10,13,18,22,19,16$, Respectively); the response percentage ranged between (2.31-1.48) and the overall score was medium; the mean of the total response was 2.38.

Table (1) also shows that the five most common manifestations of career deviation among the principals of public schools in Tulkarm governorate, according to teachers' estimations, were in descending order:

-The manager criticizes his colleagues in their absence

The Director intervenes in favor of some of the students who fail

-The manager tries to hear everything the teachers are talking about

-The principal distinguishes between teachers according to their loyalty to him regardless of their competencies

- The director makes decisions within the school individually

While the five least common manifestations of career deviation among the principals of public schools in Tulkarem according to teachers' estimations were in the following ascending order:

- The manager uses inappropriate language in the educational process

- The manager receives bribes from parents

- The Director is delayed from the official working hours

- The Director disagrees with the instructions of the financial control agencies. 
- The Director refuses the work assigned by his superiors

The researcher refers the prevalence of these phenomena to that every principal has a special relationships and friends he tries to provide service to them for his own interests. In addition, most school principals do not trust the group work and collective decision-making because they believe that a decision taken after consultation with teachers reduces the powers of school principals. As for the less common manifestations, it is due to the Ministry of Education which take measures and sanctions against school principals if they delay the official working hours or contravene the instructions of the monitoring agencies.

\subsection{The Second Question of the Study}

Are the manifestations of career deviation among the principals of the public schools in Tulkarm governorate different from the teachers' point of view according to the following variables (gender, academic qualification, years of experience)?

Sex variable: To answer the gender variable, the t-test was used for the independent sample t-test as shown in Table (2).

Table 2 .

\begin{tabular}{|c|c|c|c|c|c|c|c|}
\hline Field & $\operatorname{Sex}$ & Number & Mean & $\begin{array}{l}\text { Standard } \\
\text { deviation }\end{array}$ & $D F$ & $t$-calculated & $\begin{array}{c}\text { significance } \\
\text { level }\end{array}$ \\
\hline \multirow{2}{*}{ Career deviation } & Male & & 3.76 & 0.30 & & 0.8 & \multirow{2}{*}{0.40} \\
\hline & Femal & & 3.73 & 0.30 & & 0.8 & \\
\hline
\end{tabular}

Table (2) showed that there are no statistically significant differences at the level of significance $(\alpha=0.05)$ in the average estimates of the sample of the deviation of the principals of the public schools in Tulkarem governorate due to gender variable where the level of significance is greater than $(\alpha=0.05)$. The researcher referred this finding to the fact that there is a common understanding among all male and female principals of career deviation. This may be due to the subordination of principals and to the same working conditions in public schools. And this result is consistent with the results of the study (Omar, 2011).

Variable of Scientific Qualification: In order to answer this variable, One Way ANOVA was used to derive the values of the arithmetical averages, the standard deviations, the degrees of freedom, the calculated $F$ values, and the statistical significance level of the responses of the sample members of the study sample. Table (3) shows the results.

Table 3.

\begin{tabular}{cllllll}
\hline Field & Contrast & Total sum of squares & DF & Mean squares & F ratio & significance level \\
\hline $\begin{array}{c}\text { Career } \\
\text { deviation }\end{array}$ & Between groups & 0.40 & 3 & 0.13 & 2.15 & \multirow{2}{*}{0.09} \\
\hline
\end{tabular}

It is clear from Table (3) that there are no statistically significant differences at the level of significance $(\alpha=0.05)$ in the average estimates of the sample of the deviation of career among the principals of the public schools in Tulkarem governorate due to the variable of scientific qualification more than $(\alpha=0.05)$. The researcher attributes this result to the consistency of the general conditions and criteria for employment for many years in the Ministry of Education. The regulations and laws that govern the government schools in Tulkarm throughout their years of experience have only changed outwardly from the radical changes. That result was consistent with the results of the study of (Jabaly, 2015).

Years of experience variable: To answer this variable, One Way ANOVA was used to derive the values of arithmetic averages, standard deviations, degrees of freedom, calculated F values, and statistical level of significance of the responses of the study sample members to the total instrument of the study. Table (4) illustrates this result. 
Table 4.

\begin{tabular}{ccccccc}
\hline Field & Contrast & $\begin{array}{c}\text { Total sum of } \\
\text { squares }\end{array}$ & DF & $\begin{array}{c}\text { Mean } \\
\text { squares }\end{array}$ & $\begin{array}{c}F \\
\text { ratio }\end{array}$ & $\begin{array}{c}\text { significance } \\
\text { level }\end{array}$ \\
\hline $\begin{array}{c}\text { Organizational } \\
\text { affiliation }\end{array}$ & $\begin{array}{c}\text { Between } \\
\text { groups }\end{array}$ & 0.88 & 3 & 0.29 & 1.05 & 0.37 \\
\hline
\end{tabular}

Table (4) showed that there are no statistically significant differences at the level of significance $(\alpha=0.05)$ in the average of the estimates of the sample of the deviation of the career of the principals of the public schools in Tulkarem governorate due to the variable of scientific qualification where the level of significance is greater than $(\alpha=0.05)$, and the researcher attributes this result to the years of experience if it short or long does not affect their (principals) perception and understanding of the concept of career deviation which prevailing in their schools.

\section{Conclusions}

In light of the results of the study and its discussion, the researcher reached the following conclusions:

Lack of clear cooperation between principals and teachers in public schools.

The application of authoritarian administration by most of the principals of public schools

School principals recruit teachers in their favor by distinguishing them from others by high evaluation in order to tell them what is going on in the school among their fellow teachers.

\section{Recommendations}

In light of the objectives and results of the study, the researcher proposed the following recommendations:

1. Enhancing and promoting the culture of teamwork among the principals within the school, as well as the establishment of courses and workshops that help the principals to adhere to the ethics of their profession.

2 - Monitoring the marks of the students by the ministries of education in more precise way and claim the principals of schools and teachers to the need to fully check on the marks of students.

3 - Strengthening the role of school principals and teachers in the community and working on involve them in the civil society institutions in which they can carry out the tasks assigned to them to the fullest.

4 - Working to spread the career awareness among principals and teachers, so that they are committed to the implementation of the tasks required from them and to have the knowledge of their rights and duties.

5 - Intensification of field visits to schools by the ministries of education and work on the permanent communication between the ministry and the school administration.

\section{Acknowledgments}

It is my great pleasure to thank my university (Palestine Technical University-Kadoorie) for all the encouragement and support to achieve my research.

\section{References}

Abu Amra, Hassan (2011). Factors of Career Deviation in Technical Colleges in the Gaza Governorates from the point of view of senior management, unpublished master thesis, Gaza, Islamic University.

Al-Shammari, Ahmed, (2011). Employees' Ethics, Sixth Edition, King Saud University.

Bolin, A. \& Heatherly, L. (2001). Predictors of employee deviance: The relationship between bad attitudes and bad behavior. Journal of business and psychology, 15(3), 405-418. https://doi.org/10.1023/A:100781861.

Gentry, W. A., Ekelund, B. R. Z., Hannum, K. M. \& de Jong, A. (2015). A study of the discrepancy between self-and observer-ratings on managerial derailment characteristics of European managers. European. Journal of Work and Organizational Psychology, 16(3), 295-325. https://doi.org/10.1080/13594320701394188

Gentry, W. A., Mondore, S. P. \& Cox, B. D. (2007). A study of managerial derailment characteristics and personality preferences. Journal of Management Development, 26(9), 857-873.

Jabaly, Fatih, (2015). Career Deviation Types, Causes, and Methods of Treatment. Journal of Human and Social Sciences, 6(1), 206-183. https://doi.org/10.5901/mjss.2015.v6n6s3p160 
Judge, T. A. \& Kammeyer-Mueller, J. D. (2011). Implications of core self-evaluations for a changing organizational context. Human Resource Management Review, 21(4), 331-341. https://doi.org/10.1016/j.hrmr.2010.10.003

Kruger, P. C. (2016). The Relationship Between Personality and Biographical Factors in Absenteeism, University of south Africa, master of commerce.

McCartney, W. W. \& Campbell, C. R. (2006). Leadership, management, and derailment: A model of individual success and failure. Leadership \& Organization Development Journal, 27(3), 190-202. https://doi.org/10.1108/01437730610657712

Omar, F., Halim, F., Zainah, A. \& Farhadi, H. (2011). Stress and job satisfaction as antecedents of workplace deviant behavior. World Applied Sciences Journal, (12), 46-51.

Robbins, S. P. (2006). Essentials of Organizational Behavior, San diego State university, Seventh Edition, Prentice hall international inc.

Salami, S. O. (2010). Job stress and counterproductive work behaviour: Negative affectivity as a moderator. The Social Sciences, 5(6), 486-492. https://doi.org/10.3923/sscience.2010.486.492

Shermerhorn, J. R. \& Hunt, J. G. \& Osborn, R. N. (2014). Organizational Behavior, Seventh Edition, John Wiley \& Sons, Inc

Tabesh, Khalid (2009). Ways to Promote Working Ethics in the Palestinian Public Sector, a study on The Ministry of Health, a worksheet for the first administrative reform and development conference, the public office of employees.

Al-Thaqafi, Abdul Rahman, (2008). The Career Deviation of the General Education Teachers in Taif Governorate and the Appropriate Penalties for Controlling it as Seen by the Educational Supervisor and the General Supervisor.

Zaccaro, S. J., Rittman, A. L. \& Marks, M. A. (2001). Team leadership. The leadership quarterly, 12(4), 451-483

Yahaya, N., Yahaya, A., Tamyes, F. A., Ismail, J. \& Jaalam, S. (2010). The Effect of various modes of occupational stress, job satisfaction, intention to leave and absentism companies commission of Malaysia. Australian Journal of basic and applied sciences, 4(7), 1676-1684.

\section{Copyrights}

Copyright for this article is retained by the author(s), with first publication rights granted to the journal.

This is an open-access article distributed under the terms and conditions of the Creative Commons Attribution license (http://creativecommons.org/licenses/by/3.0/). 